\title{
Flame Retardancy and Non-slip Finish in One Step Process for Co/PET Fabrics
}

\author{
Raziye Atakan ${ }^{1 *}$, Gülay Özcan ${ }^{1}$, Elif Er ${ }^{1}$, Tansu Öztürk ${ }^{1}$, Didem Gamze Kardaş ${ }^{1}$ \\ Istanbul Technical University, Department of Textile Engineering, Gümüşsuyu Mahallesi, İnönü Cd. No:65, 34437 \\ Beyoğlu, Istanbul, Turkey
}

Corresponding Author: Raziye ATAKAN, ratakan@itu.edu.tr

\begin{abstract}
In the present study, a new flame retardancy and non-slip finishing system in one step was developed for cotton/polyester (Co/PET) fabrics. Recipes including P-N synergetic FR agent, PVP (PR)-PDCDA (Fire-off), polysilicic acid and citric acid combinations were developed and applied to cotton and $\mathrm{Co} / \mathrm{PET}$ fabrics by impregnation method. Flame retardancy (FR) properties and seam slippage resistance of treated fabrics with Fire-off/polysilicic acid systems were investigated. In addition, characterization analysis such as Fourier-transform infrared spectroscopy (FTIR), differential scanning calorimeter (DSC) were performed and tensile properties of treated fabrics were tested in order to detect any changes on mechanical properties of fabrics after treatment. Results demonstrated that Fire-off/ polysilicic acid treatment leads good FR properties (LOI >27) and seam slippage resistance (warp: $2.2 \mathrm{~mm}$, weft $1.2 \mathrm{~mm}$ ) with superior ease of application in one-step process.
\end{abstract}

\author{
ARTICLE HISTORY \\ Received: 26.07.2018 \\ Accepted: 03.01.2019

\section{KEYWORDS} \\ Flame retardancy, FR finish, \\ non-slip finish, Co/PET \\ blends, polysilicic acid
}

\section{INTRODUCTION}

Flame retardancy (FR) property is desirable in various conventional textile applications such as home textiles, apparel as well as technical textile applications in order to protect consumers from unsafe textile materials. As the most used fibers in these applications, cotton and polyester (PET) are highly flammable and they burn easily. The physical and chemical properties of cotton and PET contrast greatly; cotton is hydrophilic, whereas PET is hydrophobic. Reagents repelled by PET are absorbed by cotton. During thermal degradation, cotton chars (and at a lower temperature) than PET, which shows melting and dripping behaviour (at $260^{\circ} \mathrm{C}$ ), shrinks at its melting point and run away from the fire. However, the molten polymer cannot flow away from the flame source. In the case of Co/PET, PET component remains dispersed between the charred cotton fibers, which still maintain some structure while burning. Since cotton decomposes earlier, it becomes initial source of fuel. On the other hand, the PET component provides additional fuel to the gaseous phase at the high temperatures produced by the combustion of the cotton. Therefore, the well-known "scaffolding" effect (Figure 1) occurs $[1,2]$. Because of the different penetrability and solubility properties of the cotton and the PET, it also is difficult to find a single FR agent that will penetrate both fibres at the same time and conditions to impart a durable FR effect. Therefore, conferring the flame retardancy on $\mathrm{Co} / \mathrm{PET}$ s has been always a challenge for academia and industry.

Halogenated flame retardant systems are widely used in FR finishing processes. However their use is being limited because for environmental concerns [4-7]. Organophosphorus flame retardant agents have formaldehyde, a known carcinogen, release problem in remarkable levels $[8,9]$. These treatments may also have adverse effects on fabric strength and fabric handle properties, which limit their applicability [10, 11]. During preparation or application processes of P-N synergistic FRs, use of silica in the system is an alternative to improve both FR performance and durability.

To cite this article: Atakan R., Özcan G., Er E., Öztürk T., Kardaş D.G., 2019, “Flame Retardancy and Non-slip Finish in One Step Process for Co/PET Fabrics " Tekstil ve Konfeksiyon, 29 (1), pp:50-57. 


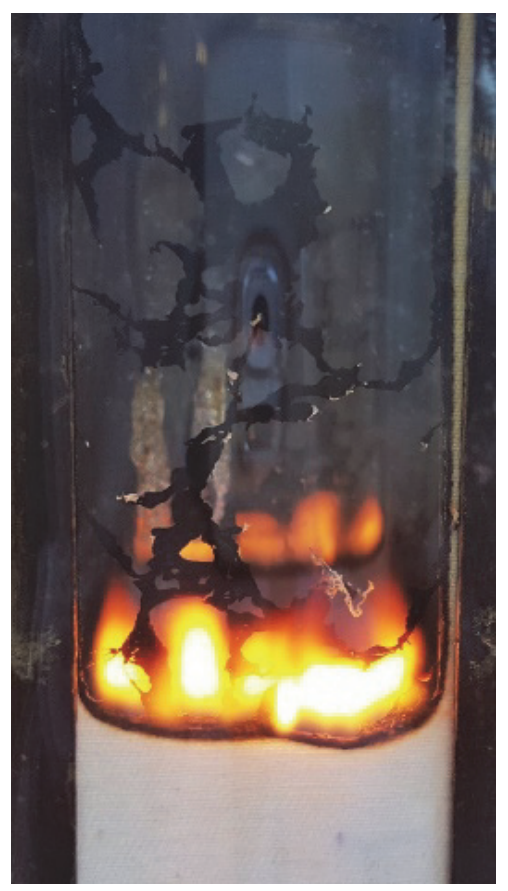

Figure 1. Skeleton effect on Co/PET fabrics

Silicone FR has become the research focus nowadays owing to its superior qualities as well as wide availability in the nature and being easy to prepare. Being exposed to elevated temperatures under oxygen of silicone containing FR agents' leads to formation of -Si-C- bonds in silicone molecules. Consequently, an inorganic combustion silica residue, which serves as a mass transport barrier, delays the volatilization of decomposition product, insulates the underlying polymer surface from the incoming external heat flux and prevent oxygen to reach the matrix [12-14]. Zhou et al [13] developed a phosphorus-nitrogen-silicon flame retardant monomer with reactive siloxy groups using $\mathrm{N}$ (diphenylphosphino)-1,1-diphenyl-N-(3-(triethoxysilyl)propyl) phosphinamine (DPTA) for cotton fabrics. It was found that the treated samples did not ignited in vertical flammability test and produced a high char formation and a low heat release during combustion according to $\mathrm{MCC}$. $\mathrm{Li}$ and coworkers [14] synthesized a phosphorous-silicone-nitrogen ternary FR agent [(1,1,3,3- tetramethyl-1,3-disilazanediyl)di2,1-ethanediyl] bis(diphenylphosphine oxide) (PSiN) and applied to epoxy composites. Results showed that the incorporation of PSiN lead to formation of char during the thermal degradation process of the epoxy thermosets. The epoxy system showed an increased LOI with the PSiN content.

Polysilicic acid has long been used in the textile industry as a non-slip finishing chemical improving resistance of seam slippage, especially for synthetic fiber based textile substrates. [15]. However, few studies have indicated that silica in the form of ions or nanoparticles derived from polysilicic acid also enhances FR performance of PET fabrics [16].

In our previous study [3], a nonformaldehyde P-N synergetic FR system, PVP (PR)-P-DCDA was synthesized by polyvinyl alcohol, hydrophilic polyester resin, phosphoric acid, and dicyandiamide and applied to $100 \%$ polyester, $100 \%$ cotton, and $50 / 50 \%$ cotton/polyester (Co/PET) fabrics by conventional padding method. Fabrics were characterized by Fourier-transform infrared (FTIR), differential scanning calorimetry (DSC) and thermogravimetric analysis (TGA), and FR properties were investigated by vertical flammability test and limiting oxygen index (LOI). Obtained data shown that PVP (PR)-P-DCDA treatment lead to enhance in char formation, and reduced their flammability via dehydration into char. In addition, it has also superior ease of application unlike "Proban" technology, which requires the use of an amnoniation chamber. At larger scale, PVP (PR)-P-DCDA has been commercialized with name "Fire-off" by Eksoy Chemical Company.

In this study, a new FR and non-slip finishing system based on Fire-off and polysilicic acid were developed. Citric acid monohydrate was used as a crosslinker to bind polysilicic acid and Fire-off to cotton fibers. Polysilicic acid gives silicate ions into finishing bath to increase the flame retardancy and it also provides resistance against seam slippage of yarns on fabric construction. Flame retardancy as well as non-slip properties of treated fabrics were investigated. Flammability, thermal, mechanical properties and chemical structure of the sample were tested according to relevant ISO standard and procedures. To do so, ISO 6940 flammability test, LOI measurement, Micro Combustion Calorimetry (MCC) test, DSC, Tensile Test and FTIR analysis were performed.

\section{MATERIALS AND METHODS}

\subsection{Materials}

Scoured $100 \%$ cotton $\left(227 \mathrm{~g} / \mathrm{m}^{2}\right.$, twill) and 35/65 Co/PET $\left(300 \mathrm{~g} / \mathrm{m}^{2}\right.$, twill) supplied from Ata Textile/Turkey were used in the experiments, representing apparel and home textile fabrics. The hydroxy-functional FR agent with the commercial name of "Fire-off" (supplied from Eksoy Chemical-Turkey) and polysilicic acid (supplied from Tanafinish Chemical-Turkey) as main chemicals and citric acid monohydrate as an auxiliary were used.

Citric acid (CA) is a well-known crosslinker of cellulose, which reacts with the cellulose hydroxyl groups through the esterification of the monohydride intermediate. The reaction mechanism is shown in Figure 2 [17]. It has usage in the FR treatments as a crosslinker to improve durability of the system [18].

Cotton fabric was chosen in the experiments to be able to observe crosslinking effect of CA between Fire-off and polysilicic acid with cotton fibers.

\subsection{Fabrics Finishing Procedure}

Different recipes were developed with combinations of polysilicic acid, Fire-off and citric acid with using different Fire-off/polysilicic acid concentrations. Effects of the concentrations on add-on values of treated fabrics after washing procedures were investigated. The washing process was performed according to ISO 6330:2012Procedure No: 4N [19]. For each washing cycle, treated fabrics were washed at $40^{\circ} \mathrm{C}$ for $30 \mathrm{~min}$ at wascator (machine Type A2) using $20 \mathrm{~g}$. ECE (reference detergent 3non-phosphate powder detergent without optical brightener and without enzymes) followed by drying. Final recipes (in Table 1) were determined according to crosslinking effects, which were revealed by statistical analysis. Subsequently, they were applied to cotton and Co/PET fabrics via pad-drycure method. 


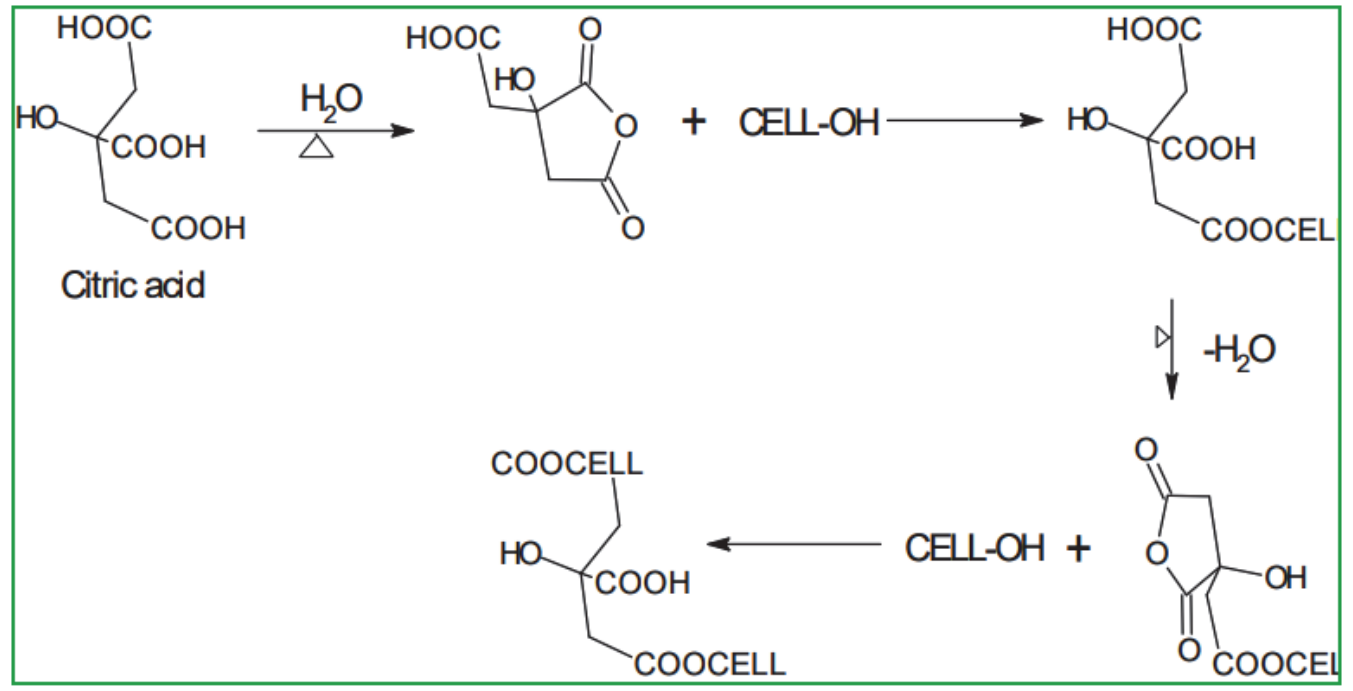

Figure 2. Mechanism of reaction of CA with cellulose [17].

Table 1. Final recipes developed in the study.

\begin{tabular}{|c|l|c|}
\hline Chemicals & \multicolumn{1}{|c|}{ Recipes } & Pick-up (\%) \\
\hline Fire-off & $\begin{array}{l}300 \mathrm{~g} / \mathrm{L} \text { Fire-off } \\
100^{\circ} \mathrm{C}-3 \text { min drying- } 180^{\circ} \mathrm{C}-3 \text { min curing }\end{array}$ & $100 \pm 3$ \\
\hline Polysilicic acid + citric acid (PA/CA) & $\begin{array}{l}80 \mathrm{~g} / \mathrm{L} \text { polysilicic acid, } 8 \mathrm{~g} / \mathrm{L} \text { citric acid } \\
100^{\circ} \mathrm{C}-3 \text { min drying- } 180^{\circ} \mathrm{C}-3 \text { min. curing }\end{array}$ & $100 \pm 3$ \\
\hline Fire-off + citric acid (Fire-off/CA) & $\begin{array}{l}300 \mathrm{~g} / \mathrm{L} \text { Fire-off }, 30 \mathrm{~g} / \mathrm{L} \text { citric acid } 100^{\circ} \mathrm{C}-3 \mathrm{~min} . \\
\text { drying- } 180^{\circ} \mathrm{C}-3 \mathrm{~min} \text {. curing }\end{array}$ & $100 \pm 3$ \\
\hline $\begin{array}{c}\text { Fire-off + Polysilicic acid +citric acid (Fire- } \\
\text { off/PA/CA) }\end{array}$ & $\begin{array}{l}350 \mathrm{~g} / \mathrm{L} \text { Fire-off, } 80 \mathrm{~g} / \mathrm{L} \text { polysilicic acid and } 8 \mathrm{~g} / \mathrm{L} \\
\text { citric acid } \\
100^{\circ} \mathrm{C} 3 \text { min. drying- } 170^{\circ} \mathrm{C}-6 \text { min. curing }\end{array}$ & $100 \pm 3$ \\
\hline
\end{tabular}

\subsection{Characterization techniques}

Fourier-transform infrared spectroscopy (FTIR) was used for characterization of chemical structure of the untreated and treated fabrics by means of Perkin Elmer spectrum One FTIR-ATR System.

The thermal stability of Co/PET fabric samples were investigated by Perkin- Elmer model differential scanning calorimeter (DSC) between the temperature of $30^{\circ} \mathrm{C}$ to $275^{\circ} \mathrm{C}$ with a heating and cooling rate of $10^{\circ} \mathrm{C} / \mathrm{min} .4-5 \mathrm{mg}$ of samples were prepared in aluminum pans. In order to prevent sample degradation, nitrogen $\left(\mathrm{N}_{2}\right)$ was used as the purge gas to provide an inert. Obtained DSC thermograms were analyzed via Pyris software in terms of melting, crystallization temperatures, and their associated enthalpies.

\subsection{Evaluation of the flame retardancy}

Vertical burning test was performed according to the ISO 6940:2006 Procedure A (surface ignition). $20 \mathrm{~s}$, which is the maximum flame application time was used in the test. Limiting oxygen index (LOI) test was conducted in according with BS 4589-2 standard. Combustion behaviors of fabrics were also assessed by Micro Cone Calorimetry (MCC) test in accordance with ASTM D7309 using $5 \mathrm{mg}$ of fabric specimens in between $125^{\circ} \mathrm{C}-740^{\circ} \mathrm{C}$ temperatures with a $1^{\circ} \mathrm{C} / \mathrm{s}$ heating rate. The flow of oxygen and nitrogen are 80 and $20 \mathrm{ml} / \mathrm{min}$, respectively.

\subsection{Evaluation of seam slippage resistance}

Seam slippage resistance of untreated and Fire-off /PA/CA treated Co/PET fabrics were tested according to ISO 13936: Textiles: Determination of the slippage resistance of yarns at a seam in woven fabrics Part 2: Fixed load method" using Instron device. The effect of Fire-off /polysilicic acid treatment on seam slippage resistance was investigated.

\subsection{Evaluation of tensile properties}

Tensile properties of untreated and Fire-off/PA/CA treated Co/PET fabrics were tested according to ISO 13934-1 "Determination of maximum force and elongation at maximum force using the strip method" in order to investigate the effect of Fire-off /polysilicic treatment on strength and elongation properties of Co/PET fabrics.

\section{RESULTS AND DISCUSSION}

\subsection{FTIR analysis}

To further investigate the efficient of flame retardant in condensed phase and verify the reaction between flame retardant and Co/PET, FTIR was employed to investigate the chemical structures of fabrics before and after treatments. FTIR spectra of untreated and Fire-off/CA and Fire-off /PA/CA treated Co/PET fabrics are depicted in Figure 3. 


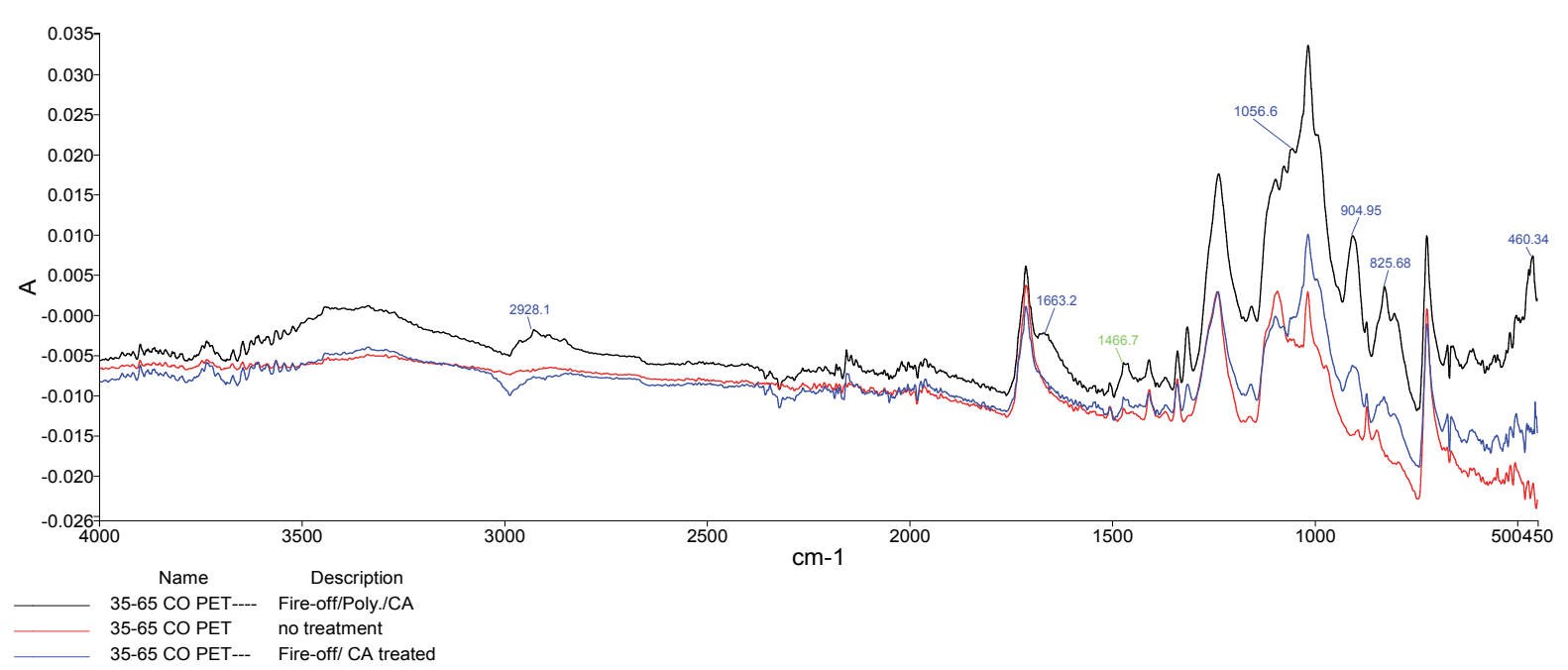

Figure 3. FTIR spectra of untreated and treated Co/PET fabrics.

From the curves in Figure 3, the spectra of control and treated Co/PET fabrics are very similar. All of them show the characteristic peaks of cellulose and PET. Characteristic absorption bands of $-\mathrm{OH}$ stretching vibrations (cellulose and PET) are seen in the range of $3500-3200 \mathrm{~cm}^{-1}$. The strong band at $1713 \mathrm{~cm}^{-1}$ is the stretching vibration of $\mathrm{C}=\mathrm{O}$ in PET. The characteristic peaks of $\mathrm{CH}$ wagging in cellulose are 1466 and $1311 \mathrm{~cm}^{-1}$. The absorption peaks of $\mathrm{C}-\mathrm{O}-\mathrm{C}$ cellulose bonds occur at 1104 and $1064 \mathrm{~cm}^{-1}$. The multiple peaks at around 1030, 1050 and $1172 \mathrm{~cm}^{-1}$ belong to the absorption of $\mathrm{C}-\mathrm{O}$, the peak at $1379 \mathrm{~cm}^{-1}$ assigns to the distortion vibration absorption of $\mathrm{C}-\mathrm{H}$. The bending vibration of $\mathrm{CH}_{2}$ in polyester is at $722 \mathrm{~cm}^{-1}$ [3, 20-23].

Compared to untreated and Fire-off/CA treated fabrics, Fireoff/CA treated fabrics showed a reducing of $\mathrm{OH}$ density peak, quite likely because of the chemical reaction between cellulose and citric acid. For treated CO/PET blends with Fire-off/CA and Fire-off/PA/CA characteristics IR absorptions of Fire-off (PVP(PR)-P-DCDA) are easily identified at around $3333\left(-\mathrm{NH}_{2}\right), 1235(\mathrm{P}=\mathrm{O}), 904(\mathrm{P}-\mathrm{O}-\mathrm{H})$, $825(\mathrm{P}-\mathrm{N})$ and $460 \mathrm{~cm}^{-1}$ (P) [3]. However, Fire-off/PA/CA treated fabrics have larger and sharper peaks 1235,1015 , 904,825 and $460 \mathrm{~cm}^{-1}$ (which are in silica region) than Fireoff/CA treated fabrics. This may be due to higher amount of Fire-off $(350 \mathrm{~g} / \mathrm{L})$ and addition of polysilicic acid in the Fireoff/PA/CA finishing system, which provides more $\mathrm{P}, \mathrm{N}$ and additionally $\mathrm{Si}$ into the fabric structures. As it is known that silica typically exhibits peaks in the region of $<1300 \mathrm{~cm}^{-1}$ in several silica modes $[24,25]$. The rocking motion of oxygen atoms, which bridge silicon atoms in siloxane bonds ( $\mathrm{Si}-\mathrm{O}$ $\mathrm{Si}$ ), occurs at $\sim 450 \mathrm{~cm}^{-1}$. The absorption at $\sim 800 \mathrm{~cm}^{-1}$ is assigned to symmetric vibrations of silicon atoms in a silixane bond and the peak observed at $\sim 1100 \mathrm{~cm}^{-1}$ corresponds the antisymmetric motion of silicon atoms in siloxane bonds. In addition, different visible peaks appeared in the spectra of Fire-off/CA/PA treated Co/PET fabrics such as at $2928 \mathrm{~cm}^{-1}$ and $1663 \mathrm{~cm}^{-1}$, which denote $\mathrm{C}-\mathrm{H}[14,23]$ and $\mathrm{H}_{2} \mathrm{O}$ [26] stretching vibrations, respectively. This result verifies that the $\mathrm{P}, \mathrm{N}$ and $\mathrm{Si}$ containing $\mathrm{FR}$ system is successfully and firmly grafted on Co/PET fibers during the treatments.

\subsection{Differential scanning calorimeter results}

Figure 4 presents DSC scans of Co/PET fabrics before and after treatment. Table 2 demonstrates the collected data derived from the DSC graphs.

It is seen from Figure 4 that the untreated Co/PET fabric melts and shows a sharp peak at $253.44^{\circ} \mathrm{C}$ with $40.17 \mathrm{~J} / \mathrm{g}$ heat absorption and develops crystallinity upon cooling from the melt at $208.59^{\circ} \mathrm{C}$ with $29.30 \mathrm{~J} / \mathrm{g}$ heat desorption. However, both Fire-off/CA and Fire-off/PA/CA treatments lead a slight decrease in melting temperatures (from 253.44 to $\sim 250{ }^{\circ} \mathrm{C}$ ), a slight increase in crystallinity temperatures (from 208.59 to $\sim 210^{\circ} \mathrm{C}$ ). In melting and cooling processes, $\mathrm{Co} / \mathrm{PET}$ fabric absorb and release more energy, namely has higher enthalpy values with both Fire-off/CA (42.59 J/g for melting and $37.45 \mathrm{~J} / \mathrm{g}$ for cooling) and Fire-off/PA/CA (39.60 $\mathrm{J} / \mathrm{g}$ for melting and $35.88 \mathrm{~J} / \mathrm{g}$ for cooling) treatments. These results appealed that thermal stability of Co/PET fabrics has a slight change with both Fire-off/CA and Fire-off/PA/CA treatments.

Table 2. Collected data from DSC thermograms.

\begin{tabular}{ccccc}
\hline Treatment & $\begin{array}{c}\mathbf{T}_{\mathbf{m}} \\
\left({ }^{\circ} \mathbf{C}\right)\end{array}$ & $\Delta \mathbf{H}_{\mathbf{m}}(\mathbf{J} / \mathbf{g})$ & $\mathbf{T}_{\mathbf{c}}\left({ }^{\circ} \mathbf{C}\right)$ & $\begin{array}{c}\Delta \mathbf{H}_{\mathrm{c}} \\
(\mathbf{J} / \mathbf{g})\end{array}$ \\
\hline \hline- & 253.44 & 40.17 & 208.59 & 29.30 \\
Fire-off/CA & 250.68 & 42.59 & 210.92 & 37.45 \\
Fire-off/PA/CA & 249.7 & 39.60 & 210.25 & 35.88 \\
\hline
\end{tabular}




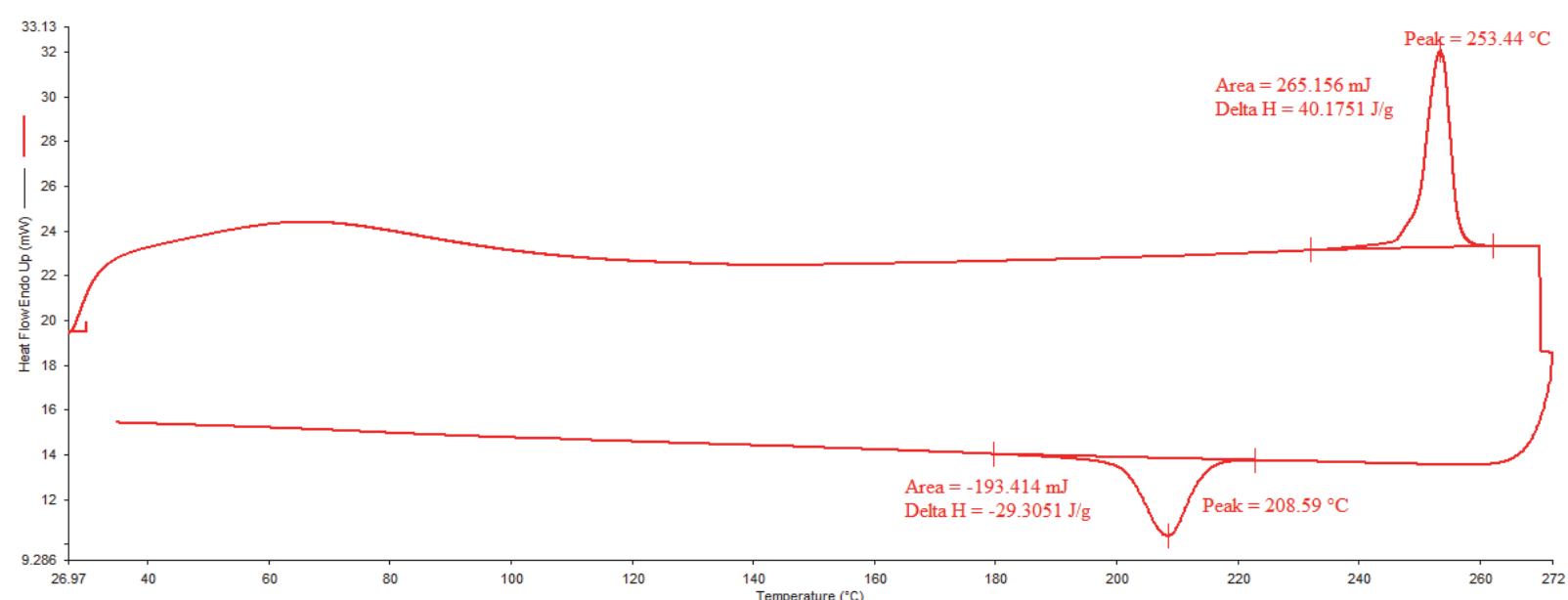

a)

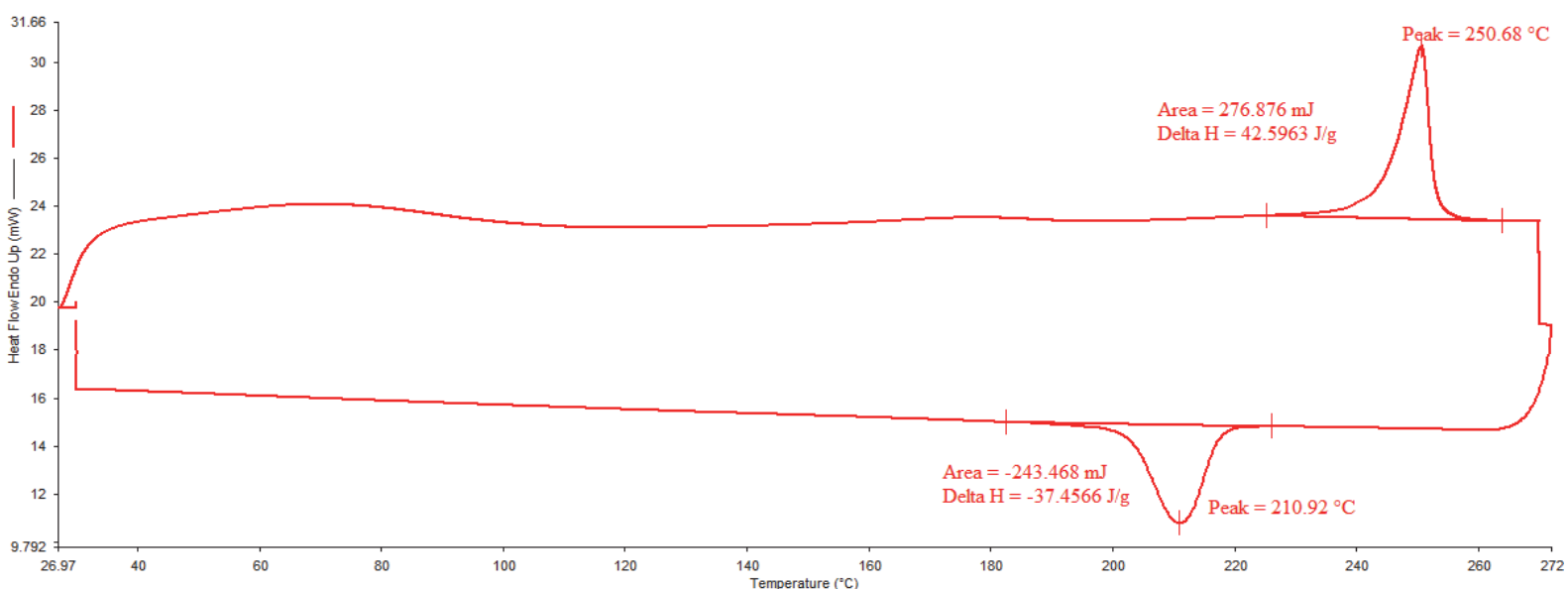

b)

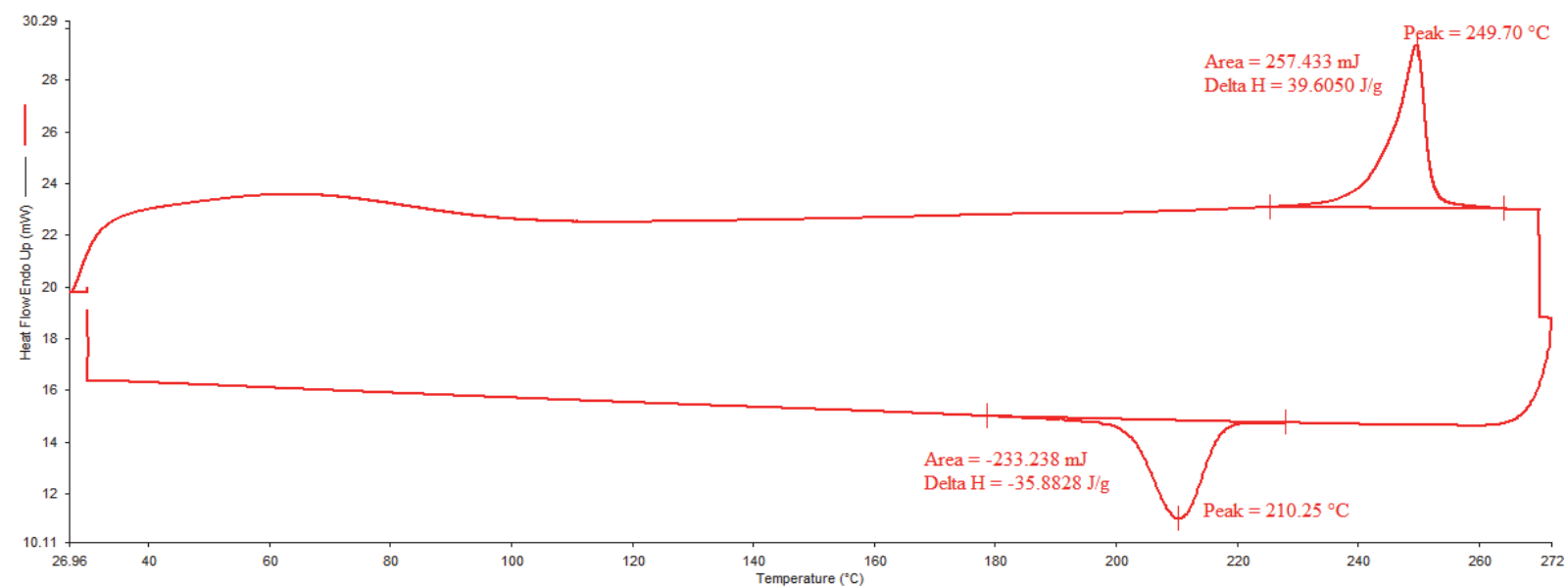

c)

Figure 4. DSC graphs of Co/PET fabrics: (a) untreated fabrics; (b) Fire-off/CA treated fabrics; (c) Fire-off/PA/CA treated fabrics.

\subsection{Evaluation of the flame retardancy}

Flammability of treated fabrics was tested according to ISO 6940 with $20 \mathrm{~s}$ of flame subjection before and after washing process. Ignition times of samples are shown in Table 3. It can be seen that for untreated cotton and Co/PET fabrics the flame runs through the whole samples so quickly and damages all without any char length formed within 20 s. For PA/CA treated fabrics, Co/PET samples had ignition time of $21 \mathrm{~s}$, which indicate that polysilicic acid/citric acid combination provides some FR features on Co/PET fabrics by delaying the ignition around $10 \mathrm{~s}$. However, all the Fire- 
off/PA/CA treated fabrics stopped the flame propagation immediately after flame subjection, without after-flame and after-glow and large amount of chars retains at the igniting area of treated fabrics. After one washing cycle, PA/CA treated fabrics lost their FR efficiency, however their ignition times are still higher than untreated ones. Fire-off/PA/CA treated Co/PET samples still showed the resistance to ignition (18 s). These results verify that the incorporation of $\mathrm{P}, \mathrm{N}$ and $\mathrm{Si}$ was in favor of the char formation during the thermal decomposition of Co/PET fabrics.

The LOI value, which is an evaluation method of the ignition and ease of extinction of a sample, is widely used in both academic and industrial research [27-29]. Table 4 exhibits LOI test results associated with related add-ons (\%) of untreated and treated cotton and Co/PET fabric samples.

It is obviously seen from Table 4, the LOI values of untreated fabrics are around 18.5. PA/CA treated samples show approximately the LOI value of 20-21, which are higher than the untreated samples. On the other hand, the LOI values of Fire-off, Fire-off /CA and Fire-off/PA/CA treated samples are significantly higher (more than 26 , which is the FR standard) than that of the untreated samples.

In detail, LOI values of Fire-off/CA treatment lead an increase in LOI values (from 26.2 to 26.7 for Co/PET) compared to those of Fire-off treated samples. With the addition of polysilicic acid the system (P-N-Si synergism) the
LOI increased 27.2 for Co/PET and 28.7 for cotton. The incorporation of $\mathrm{P}-\mathrm{N}-\mathrm{Si}$ results in a strong enhancement of $\mathrm{LOI}$ value due to the attribution to FR effects of the three elements $(P, N$ and $\mathrm{Si})$ in the system.

The FR behaviors of untreated and treated Co/PET fabrics with Fire-off and Fire-off/PA/CA are further assessed by micro combustion calorimetry (MCC). The Heat Release Rate (HRR) curves of untreated and treated samples are exhibited in Figure 5 and the corresponding data are listed Table 5. It can be seen from Figure 5 that the presence of $P$, $\mathrm{N}$ in Fire-off and $\mathrm{P}, \mathrm{N}$, and $\mathrm{Si}$ in Fire-off/PA/CA decrease the onset decomposition temperature for treated Co/PET fabrics. This might be due to the degradation of phosphoruscontaining compound during combustion may catalyze the dehydration of cellulose [30]. It is seen from Table 5 that both peak heat release rate ( $\mathrm{pHRR}$ ) and total heat release (THR) values of Fire-off/CA/PA are greatly reduced by the synergism of $\mathrm{P}, \mathrm{N}$ and $\mathrm{Si}$. For instance, the pHRR value of Fire-off/CA/PA is $161.89 \mathrm{~W} / \mathrm{g}$, which is approximately $22 \%$ lower than that of untreated fabric $(206.77 \mathrm{~W} / \mathrm{g})$. Compared to mass loss rates of fabrics before and after treatments, untreated fabric has $90 \%$ of mass loss, while Fire-off/PA/CA treated $82 \%$. This indicated that the presence of $\mathrm{P}, \mathrm{N}$ and $\mathrm{Si}$ in FR system leads to an increase of the residual char that further inhibits the transfer of heat. Therefore, these results are consistent with those of vertical flammability and LOI tests.

Table 3. Ignition times of samples (ISO 6940).

\begin{tabular}{cccccc}
\hline Fabric Type & $\begin{array}{c}\text { Untreated } \\
\text { fabrics }\end{array}$ & $\begin{array}{c}\text { PA/CA } \\
\text { treated }\end{array}$ & $\begin{array}{c}\text { PA/CA treated } \\
\text { after 1 wash }\end{array}$ & $\begin{array}{c}\text { Fire-off /PA/CA } \\
\text { treated }\end{array}$ & $\begin{array}{c}\text { Fire-off /PA/CA treated } \\
\text { after 1 wash }\end{array}$ \\
\hline \hline Cotton & $7 \mathrm{~s}$ & $8 \mathrm{~s}$ & $8 \mathrm{~s}$ & No ignition & $8 \mathrm{~s}$ \\
Co/PET & $10 \mathrm{~s}$ & $21 \mathrm{~s}$ & $11 \mathrm{~s}$ & No ignition & $18 \mathrm{~s}$ \\
\hline
\end{tabular}

Table 4. LOI values of samples (BS 4589-2)

\begin{tabular}{cccccccccc}
\hline \multirow{2}{*}{$\begin{array}{c}\text { Fabric } \\
\text { Type }\end{array}$} & $\begin{array}{c}\text { Untreated } \\
\text { samples }\end{array}$ & \multicolumn{2}{c}{$\begin{array}{c}\text { Fire-off treated } \\
\text { samples }\end{array}$} & \multicolumn{2}{c}{$\begin{array}{c}\text { PA/CA treated } \\
\text { samples }\end{array}$} & \multicolumn{2}{c}{$\begin{array}{c}\text { Fire-off /CA treated } \\
\text { samples }\end{array}$} & \multicolumn{2}{c}{$\begin{array}{c}\text { Fire-off/PA/CA treated } \\
\text { samples }\end{array}$} \\
\cline { 2 - 11 } & LOI & $\begin{array}{c}\text { Add-on } \\
(\%)\end{array}$ & LOI & $\begin{array}{c}\text { Add-on } \\
(\%)\end{array}$ & LOI & $\begin{array}{c}\text { Add-on } \\
(\%)\end{array}$ & LOI & $\begin{array}{c}\text { Add-on } \\
(\%)\end{array}$ & LOI \\
\hline \hline Cotton & 18.5 & 16.5 & 27.3 & 1.2 & 21.0 & 23.6 & 27.8 & 26 & 28.7 \\
Co/PET & 18.6 & 18.8 & 26.2 & 1.3 & 20.3 & 21.5 & 26.7 & 28 & 27.2 \\
\hline
\end{tabular}

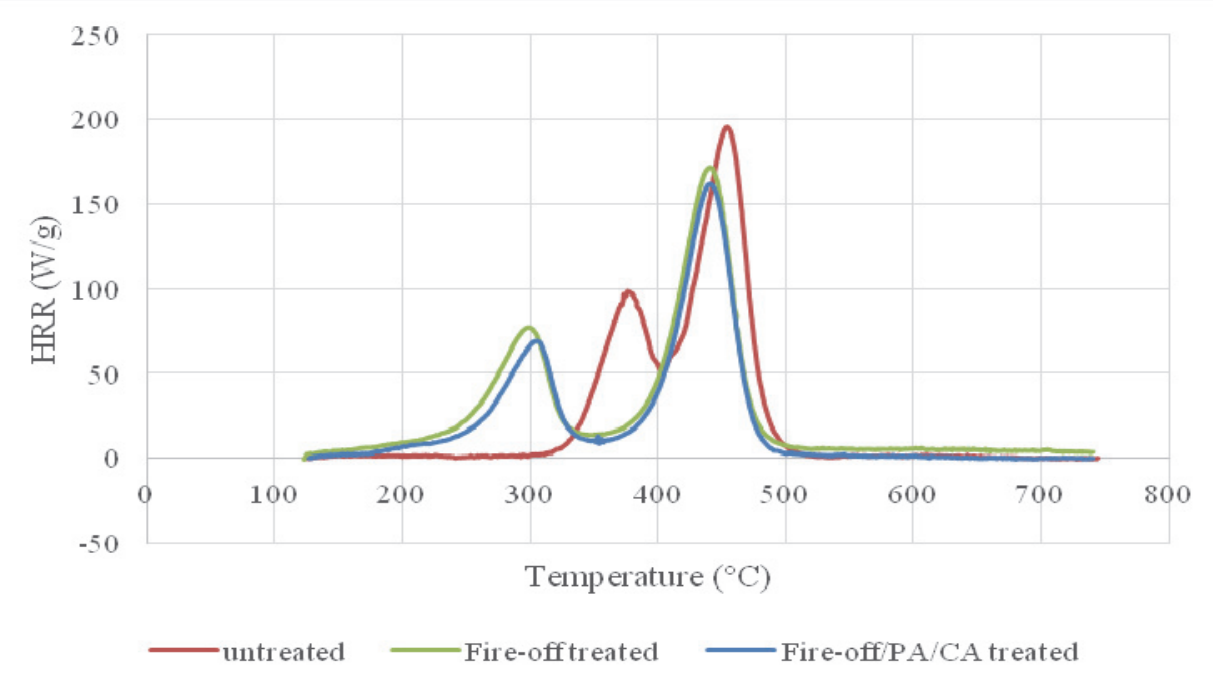

Figure 5. Heat release rates of untreated and treated Co/PET fabrics. 
Table 5. Summary of MCC results of Co/PET fabric.

\begin{tabular}{ccccc}
\hline Treatment & $\mathbf{p H R R}(\mathbf{W} / \mathbf{g})$ & $\mathbf{T}_{\max }\left({ }^{\circ} \mathbf{C}\right)$ & THR $(\mathbf{k J} / \mathbf{g})$ & Mass loss $(\%)$ \\
\hline \hline- & 206.77 & 452.2 & 17.1 & 90 \\
Fire-off & 170.9 & 440.27 & 14.83 & 84 \\
Fire-off/PA/CA & 161.89 & 440.75 & 13.16 & 82 \\
\hline
\end{tabular}

Based on these results, it is indicated that Fire-off/CA/PA treatment as a $\mathrm{P}-\mathrm{N}-\mathrm{Si}$ reactive $\mathrm{FR}$ system can well improve the flame-retardant ability of Co/PET fabrics.

\subsection{Evaluation of seam slippage resistance}

Seam slippage, which is very important for apparel manufacturers and customers, is closely related to seam quality. It depends on fabric and sewing thread properties as well as the effects of applied mechanical forces on the seam, which causes the problem of slipping of weft yarns over warp, or warp yarns over weft. Thus, it causes to a distortion of the sewing surface and reduces the product life $[31,32]$. The results of slippage resistance of Co/PET fabrics are shown in Table 6 . According to the results obtained in Table 6, untreated Co/PET fabrics has $2.5 \mathrm{~mm}$ for warp and $1.7 \mathrm{~mm}$ for weft seam slippage, whereas treated ones has lower seam openings $(2.2 \mathrm{~mm}$ for warp and $1.2 \mathrm{~mm}$ for weft) under the tensile load of $180 \mathrm{~N}$. In addition, no breakage of sewing thread is observed during the test. For treated fabrics, approximately $1 \mathrm{~mm}$ less seam openings were measured for both direction. Results indicated that Fire-off /PA/CA treatment improved the seam slippage resistance (12\% for warp, $29 \%$ for weft) for Co/PET blends.

\subsection{Evaluation of tensile properties}

Textile fabrics exposed to finishing process under various conditions for instance pressure (such as padding process), temperature and $\mathrm{pH}$, which impact their mechanical properties [33]. Table 7 illustrates the effect of Fire-off /PA/CA finishing process on the tensile properties of Co/PET fabrics. It is clearly seen that the tensile strength slightly declines with treatment process (from 1904.82 to $1869.91 \mathrm{~N}$ ). This decline might be in relation to hard processing of pad-dry-cure, which associated with high temperature that might degrade glucose ether linkage decreasing the chain length of fibres. Conversely, the elongation values increase slightly with the treatment (from 25.35 to $26.41 \%$ ). Fabrics are still strong with better elasticity to be applied to indoor (such as carpets, curtains, bedding etc.) and clothing applications.

Table 6. Seam slippage of untreated and Fire-off /PA/CA treated Co/PET fabric.

\begin{tabular}{cccc}
\hline Seam slippage & Untreated fabric & Fire-off $/ P A / C A$ treated & Improvement \% \\
\hline \hline warp slippage & $2.5 \mathrm{~mm}$ & $2.2 \mathrm{~mm}$ & $12 \%$ \\
weft slippage & $1.7 \mathrm{~mm}$ & $1.2 \mathrm{~mm}$ & $29 \%$ \\
\hline
\end{tabular}

Table 7. Tensile test results of untreated and treated Co/PET fabrics.

\begin{tabular}{rcc}
\hline Treatment & Maximum Force (N) & Elongation (\%) \\
\hline \hline- & $1904.82 \pm 19.61$ & $25.35 \pm 0.35$ \\
$C V$ & $1.03 \%$ & $1.37 \%$ \\
Fire-off /PA/CA & $1869.91 \pm 50.69$ & $26.41 \pm 0.26$ \\
$C V$ & $2.71 \%$ & $1.00 \%$ \\
\hline
\end{tabular}

\section{CONCLUSION}

In this work, a novel flame retardant and non-slip finish using halogen-free and formaldehyde-free FR Fire-off along with Polysilicic acid were developed and successfully applied to cotton and Co/PET fabrics via pad-dry-cure method. The treatment was facile and did not damage the fibers despite high temperatures in curing process. Fabrics show excellent vertical flame resistance after the treatment. Treated Co/PET samples show self-extinguished behaviour in combustion process and form a large amount of char with no burning time. Moreover, this $\mathrm{P}-\mathrm{N}-\mathrm{Si}$ containing FR system results in a strong enhancement of LOI value, more than 27 . The obtained results showed that polysilicic acid could be used for cellulosic blends with Fire-off to improve FR performance. In addition, Fire-off/Polysilicic acid treatment has a beneficial effect on seam slippage resistance of Co/PET fabrics. Therefore, Fire-off /PA/CA system is an excellent FR and non-slip system for Co/PET fabrics in only one step finishing process and has a wide potential application in furnishings, home decoration and industrial fields and so on.

\section{ACKNOWLEDGMENTS}

The authors gratefully acknowledge the funding by I.T.U BAP, under grants of 39775 project. We wish to thank Ata Textile for fabric supply. We extend our appreciation to Prof. Dr. Nevin Çiğdem Gürsoy for laboratory facilities in "I.T.Ü Evrensel Tekstil Merkezi" to perform chemical application and Prof. Dr. Mustafa Üreyen and Res. Asst. Elif Kaynak Uraz for laboratory facilities to perform Micro Combustion Calorimetry (MCC) Test in "Anadolu Üniversitesi Sivil Havacılık Araştırma ve Uygulama Merkezi”. 


\section{REFERENCES}

1. Horrocks, A., et al., Developments in flame retardant textiles-a review. Polymer Degradation and stability, 2005. 88(1): p. 3-12.

2. Horrocks, A.R. and D. Price, Advances in fire retardant materials. 2008: Elsevier.

3. Atakan, R., et al., Development of a flame retardant chemical for finishing of cotton, polyester, and CO/PET blends. Journal of Industrial Textiles, 2018: p. 1528083718772303.

4. Zhao, X., Synthesis and application of a durable phosphorus/silicon flame-retardant for cotton. The Journal of The Textile Institute, 2010. 101(6): p. 538546.

5. M. Neisius, T.S., S. Liang and S. Gaan, Flame retardant finishes for textiles, in Functional Finishes for Textiles, R. P, Editor. 2015, Woodhead Publishing Ltd: Cambridge-England. p. 429-452.

6. Van der Veen, I. and J. de Boer, Phosphorus flame retardants: properties, production, environmental occurrence, toxicity and analysis. Chemosphere, 2012. 88(10): p. 1119-1153.

7. Cordner, A., M. Mulcahy, and P. Brown, Chemical regulation on fire: rapid policy advances on flame retardants. Environmental science \& technology, 2013. 47(13): p. 7067-7076.

8. Gaan, S., et al., Thermal degradation of cellulose acetate in presence of bis-phosphoramidates. Journal of Analytical and Applied Pyrolysis, 2011. 90(1): p. 33-41.

9. Morgan, A.B. and C.A. Wilkie, The non-halogenated flame retardant handbook. 2014: John Wiley \& Sons.

10. Horrocks, A., Flame retardant finishes and finishing. Textile finishing, 2003. 2: p. 62-101.

11. Schindler W D, H.P.J., Flame retardant finishes, in Chemical Finishing of Textiles. 2004, Woodhead Publishing: Cambridge, UK. p. $98-116$.

12. Choudhury, A.K.R., Flame- and fire-retardant finishes, in Principles of Textile Finishing. 2017, Woodhead Publishing: UK. p. $217-218$.

13. Zhou, T., et al., Synthesis of a novel flame retardant phosphorus/nitrogen/siloxane and its application on cotton fabrics. Textile Research Journal, 2015. 85(7): p. 701-708

14. Li, Z.S., et al., Synthesis and characterization of novel phosphorous - silicone - nitrogen flame retardant and evaluation of its flame retardancy for epoxy thermosets. Journal of Applied Polymer Science, 2014. 131(24).

15. Schindler W D, H.P.J., Non-slip finishes, in Chemical Finishing of Textiles. 2004, Woodhead Publishing: Cambridge- UK. p. 117-120.

16. Carosio, F., et al., Layer-by-layer assembly of silica-based flame retardant thin film on PET fabric. Polymer Degradation and Stability, 2011. 96(5): p. 745750.

17. Rojas, J. and E. Azevedo, Functionalization and crosslinking of microcrystalline cellulose in aqueous media: A safe and economic approach. Int. J. Pharma. Sci. Rev. Res, 2011. 8: p. 28-36.

18. Mengal, N., et al., Citric acid based durable and sustainable flame retardant treatment for lyocell fabric. Carbohydrate polymers, 2016. $153:$ p. $78-88$.

19. ISO, E., Textiles - Domestic washing and drying procedures for textile testing. 2012: Brussels.

20. Yang, Z., et al., A novel halogen - free and formaldehyde - free flame retardant for cotton fabrics. Fire and Materials, 2012. 36(1): p. 31-39.

21. Yang, Z., et al., A durable flame retardant for cellulosic fabrics. Polymer degradation and stability, 2012. 97(11): p. $2467-2472$.

22. Gao, W.-W., G.-X. Zhang, and F.-X. Zhang, Enhancement of flame retardancy of cotton fabrics by grafting a novel organic phosphorous-based flame retardant. Cellulose, 2015. 22(4): p. 2787-2796.

23. Raucci, M., et al., Effect of citric acid crosslinking cellulose - based hydrogels on osteogenic differentiation. Journal of Biomedical Materials Research Part A, 2015. 103(6): p. 2045-2056.

24. Fidalgo, A. and L.M. Ilharco, The defect structure of sol-gel-derived silica/polytetrahydrofuran hybrid films by FTIR. Journal of Non-Crystalline Solids, 2001. 283(1-3): p. 144-154.

25. Patwardhan, S.V., et al., Conformation and assembly of polypeptide scaffolds in templating the synthesis of silica: an example of a polylysine macromolecular "switch". Biomacromolecules, 2006. 7(2): p. 491-497.

26. Choudhary, R., S. Koppala, and S. Swamiappan, Bioactivity studies of calcium magnesium silicate prepared from eggshell waste by sol-gel combustion synthesis. Journal of Asian Ceramic Societies, 2015. 3(2): p. 173-177.

27. Yang, C.Q. and Q. He, Applications of micro-scale combustion calorimetry to the studies of cotton and nylon fabrics treated with organophosphorus flame retardants. Journal of analytical and applied pyrolysis, 2011. 91(1): p. 125-133.

28. Salmeia, K.A., S. Gaan, and G. Malucelli, Recent advances for flame retardancy of textiles based on phosphorus chemistry. Polymers, $2016.8(9)$ : p. 319.

29. Horrocks, A.R., M. Tune, and L. Cegielka, The burning behaviour of textiles and its assessment by oxygen-index methods. Textile Progress, 1988. 18(1-3): p. 1-186.

30. Hu, S., Y. Hu, and L. Song, The potential of functionalized organic-inorganic hybrid materials for influencing the thermal stability of cotton fabrics. Science of Advanced Materials, 2012. 4(9): p. 985-993.

31. Pasayev, N., M. Korkmaz, and D. Baspinar, Investigation of the techniques decreasing the seam slippage in chenille fabrics (Part I). Textile Research Journal, 2012. 82(9): p. 855-863.

32. Sülar, V., et al., A comparative study on seam performance of cotton and polyester woven fabrics. The journal of the Textile Institute, 2015. 106(1): p. 1930.

33. Hashemikia, S. and M. Montazer, Sodium hypophosphite and nano TiO2 inorganic catalysts along with citric acid on textile producing multi-functional properties. Applied Catalysis A: General, 2012. 417: p. 200-208. 